\title{
Variations in the Motivations of Environmental Citizen Scientists
}

\author{
SARAH WEST (D)
}

ALISON DYKE D

RACHEL PATEMAN (D)

*Author affiliations can be found in the back matter of this article

\begin{abstract}
Understanding motivations is important because appealing to and fulfilling motivations helps citizen science projects recruit and retain participants. We summarise the literature around motivations, drawing on key theories from volunteering more broadly and building on this with additional motivations identified in studies of citizen scientists. We also examine what is known about differences in motivations between demographic groups. We then report on a survey of 613 environmental citizen scientists in Great Britain; they were asked to select from a list of motivations derived from the literature. We used hierarchical cluster analysis to group respondents by types of motivations held. Two clusters were dominated by people holding Values motivations (concern for others or the environment), both of which had high proportions of older people and people identifying as from white ethnic groups. A third cluster included people with Egoism motivations (participating to learn something or further one's career) and Values motivations. This cluster had a higher proportion of some commonly underrepresented groups than the overall sample, including younger people, people identifying as from minority ethnic groups and people in lower socioeconomic groups. Two further clusters also had higher proportions of people from minority ethnic groups than the overall sample, one dominated by those who participated because they were asked to, and the other by people who held other motivations not in our list. We use insights on participant motivations from the literature and survey to make recommendations to those wishing to recruit and retain citizen scientists, particularly those from underrepresented groups.
\end{abstract}

CORRESPONDING AUTHOR:

\section{Sarah West}

Stockholm Environment Institute, Department of Environment and Geography, University of York, GB

sarah.west@york.ac.uk

\section{KEYWORDS:}

demographics; ethnicity; socioeconomic status; diversity; recruitment; representation

TO CITE THIS ARTICLE:

West, S, Dyke, A and Pateman, R. 2021. Variations in the Motivations of Environmental Citizen Scientists. Citizen Science: Theory and Practice, 6(1): 14, pp. 1-18. DOI: https:// doi.org/10.5334/cstp.370 


\section{INTRODUCTION}

Citizen science has many potential benefits for science and for its participants. In order to realise these myriad benefits, however, participants need to be recruited to and, in some cases, retained in projects. Recruiting and retaining participants can be expensive and time-consuming (Merenlender et al. 2016; Wald, Longo, and Dobell 2016) and so it is important to plan these activities carefully. There are a range of factors that affect the likelihood someone will start and continue participating, including personal circumstances and demographics, awareness of the opportunity, and organisational factors (Penner 2002; see West and Pateman 2016 for a more detailed discussion). Also important are people's motivations. Motivations are the subjective reasons people give for their behaviours (Aitamurto and Galli 2017) and are known to vary between people, with different people in the same role for different reasons (Clary and Snyder 1999). Paying heed to the range of motivations of potential participants will increase the number of people taking part, as people will only begin and sustain participation in projects that meet their motivations (West and Pateman 2016), which is known as the "matching hypothesis" (Snyder and Omoto 2008). Fulfilling motivations can also increase the quality of participants' experiences in projects, leading to enhanced outcomes for participants and for the project (Shirk et al. 2012; Alender 2016).

Understanding the motivations of citizen science participants is a growing area of research. Whereas a 2015 review found only $3 \%$ of papers in the field of citizen science covered participant motivations or the benefits of taking part in citizen science (Follett and Strezoy 2015), several studies have been published since this time that have begun to improve our understanding (e.g., Schuttler et al. 2018; Wehn and Almomani 2019). Furthermore, researchers can draw on related fields such as volunteering. Citizen science participation can be seen as a form of volunteering (West and Pateman 2016), and this larger and longer-established field has many relevant studies that the field of citizen science can build on. We start this paper by reviewing the literature on motivations in volunteering and citizen science. We present a summary of the key theories used to describe and categorise motivations, how these interrelate, and the range of motivations that have been identified. We focus on studies of participants in environmental projects because such projects are prominent in volunteering and in citizen science, and volunteering is relevant to the study we present in the second part of the paper.

One area we pay particular attention to is how motivations differ between demographic groups. This is important because some demographic groups (at least in Western countries) are underrepresented in citizen science, with gender, age, ethnicity, education, and socioeconomic status all affecting the likelihood of participation (NASEM 2018; Pateman et al. in press). These biases in participation can lead to unrepresentative findings and misinterpretation of results (Toms and Newson 2006), and individuals and communities who are not included miss the benefits that can come from participation. Understanding how motivations differ between groups could, therefore, help target retention and recruitment strategies towards underrepresented groups.

In the second part of this paper, we present a study of the motivations of 613 environmental citizen scientists in Great Britain. Using motivations identified in the literature review, we evaluate the relative importance of each of these for this group. We also examine whether types of participants can be identified based on the range of motivations they hold, and how motivations differ between demographic groups. The findings of this study are intended to be useful for those designing recruitment and retention strategies for citizen science projects, particularly those seeking to include currently underrepresented groups.

\section{REVIEW OF LITERATURE ON MOTIVATIONS IN VOLUNTEERING AND CITIZEN SCIENCE METHODS}

We first conducted a literature search using the terms "volunteer motivation"" "-healthy volunteer" (to exclude the vast medical trial volunteer literature) and "systematic review" on Google Scholar and Web of Science core collection. We used this literature to identify the most widely used theories and categorisations of volunteer motivations, which are summarised in Figure 1. We supplemented this with our knowledge of studies of environmental volunteers, which we used to identify additional motivations specific to this group. We then conducted a literature search with the terms "citizen science" and "motivation"” and used results to summarise the current knowledge on motivations of citizen science participants, to explore how theories that were developed for volunteers have been applied in citizen science, and to identify additional motivations not described in the volunteering literature. Again, we primarily focussed on environmental citizen science. In Figure 1, we show how the motivations of environmental volunteers and citizen scientists relate to and build on those identified for volunteers in general.

\section{VOLUNTEER MOTIVATIONS}

A recent systematic review of the volunteering literature (Rutherford et al. 2019) states that the most widely used 


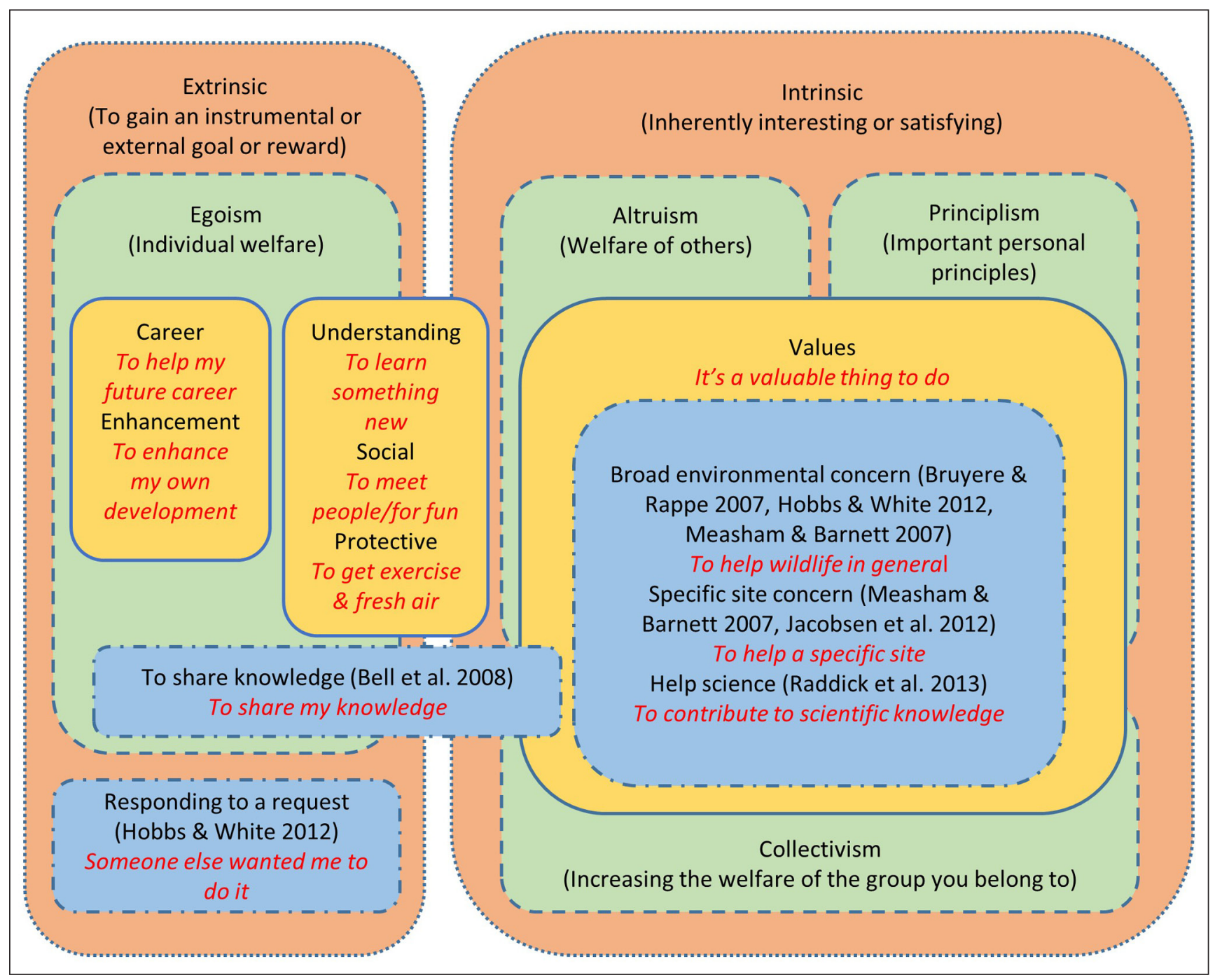

Figure 1 Motivations categories. Boxes show how motivations categories map onto each other and from where they are derived. Orange boxes with short-dashed outlines are from Finkelstien (2009); green boxes with long-dashed outlines are from Batson, Ahmad, and Tsang (2002); yellow boxes with solid outlines are from Clary and Snyder (1999); and blue boxes with short-long-dashed outlines are from other sources. Red italic text indicates the motivations categories presented to survey respondents.

model of motivations is the functional approach, which has its foundations in the field of psychology. This model states that volunteering serves different psychological functions for different people. It identifies six motivations categories, called the Volunteer Functions Inventory (VFI) (Clary and Snyder 1999). These are Values (expressing altruistic and humanitarian values), career (to benefit one's future career), Enhancement (to improve oneself), Understanding (to learn new things), Social (to meet new people and/or because volunteering is socially desirable), and Protective (to address personal problems or reducing negative feelings). Although the VFI has been critiqued by some (for example, Shye (2010) argues that the categories are neither exhaustive nor exclusive, and it is unclear how they interrelate), it has been very widely used, including in the environmental volunteering and citizen science fields.
Also from the field of psychology, Finkelstien (2009) defines motivations for volunteering as intrinsic (it is inherently interesting, satisfying, or aligned to one's values) or extrinsic (to obtain a goal or reward that is instrumental or external to oneself, such as respect [Aitamurto, Landemore, and Galli 2017]). Most of the motivations from the VFI could be considered to have both extrinsic and intrinsic elements; for example, Understanding motivations can be extrinsic because they relate to one's own personal development as well as intrinsic because they relate to finding something inherently interesting. Career motivations, however, are more closely aligned with extrinsic motivations, and Values motivations are more closely aligned with intrinsic motivations (Figure 1).

An alternative categorisation comes from social psychology; Batson, Ahmad, and Tsang (2002) classify 
motivations for engaging in community activities as Egoism, for the individual's welfare, Altruism, to increase the welfare of others, Collectivism to support a group, and Principlism, upholding personal principles. Egoism motivations could have extrinsic and intrinsic elements, whereas the other categories are more clearly intrinsic and align with the Values motivations from the VFI (Figure 1; Asingizwe et al. 2020).

When looking at volunteers engaging in nature conservation activities, Bruyere and Rappe (2007) and Van Den Berg, Dann, and Dirkx (2009) found all VFI motivations to be present except for the Protective (addressing negative feelings) motivation. Bruyere and Rappe (2007) found Values motivations manifested as wanting to help the environment (Figure 1), as well as the more general motivation for participating because it aligns with one's values. Also focusing on natural resource volunteers, Measham and Barnett (2008) and Jacobsen et al. (2012) found that, in addition to broad environmental concern, attachment to a particular site was also an important motivator for environmental volunteers (Figure 1).

\section{Motivations of citizen science participants}

Wehn and Almomani (2019) analysed the literature on motivations of environmental citizen scientists and noted the majority of studies do not state explicitly a theory that underpins them. Those that do, have mostly based their categorisation on the functional approach (Asingizwe et al. 2020). Across studies based on the VFI, Values motivations appear to be the most common drivers for citizen science participation (e.g., Koss et al. 2019; Alender 2016; Pages et al. 2019). Projects that have a strong educational focus, however, have found Egoism motivations to be important (e.g., Domroese and Johnson 2017; Merelender et al. 2017). By contrast, Wright et al. (2015) modified the VFI and found recreation or nature-based motivations (considered by Alender (2016) to be a Protective motivation) to be most important, followed by personal values, personal growth, and social interaction.

A smaller number of studies have used the Batson, Ahmad, and Tsang (2002) categorisation; for example, Rotman et al. (2012) studied a variety of ecological citizen science projects and found motivations could be divided into Egoism, Collectivism, and Principlism. McAteer et al. (2021) also used this categorisation for their study of marine citizen science volunteers. Other studies have used their own classifications, although the categories largely overlap with either the VFI or the Batson, Ahmad, and Tsang (2002) categories (McAteer et al. 2021). For example, Domroese, and Johnson (2017) asked "Bee Watchers" about their motivations, and divided those they identified into learning, values, outdoors, social, and a small number of other miscellaneous functions.
Studies of citizen scientists have identified additional motivations to those identified in the volunteering literature. Further Values motivations include wanting to help science (Raddick et al. 2013) and to share knowledge with others (Bell et al. 2008), which could also have extrinsic elements such as wanting to gain status (Figure 1). Hobbs and White (2012) found some citizen scientists participated because someone else asked them to, which is an extrinsic motivation (Figure 1).

Finally, some studies have looked at how citizen science participants' motivations change over time (e.g., Rotman et al. 2012; Carballo-Cárdenas and Tobi 2016). Asingizwe et al. (2020), for example, explored this in their malarial mosquito monitoring project in Rwanda and found that initially participants $(n=30)$ were motivated by curiosity, by a desire to learn new things, by a desire to help others, and by desire to contribute to controlling malaria, but the most important motivations given for continuing to be involved were having an opportunity to learn, and feeling like it was useful for researchers and for controlling malaria.

\section{Variations in motivations between demographic groups}

The volunteering literature has begun to explore how motivations vary between demographic groups. Rutherford et al.'s (2019) systematic review of volunteering literature noted that motivation varies by age, with Egoism motivations being particularly important for younger people who may be volunteering to gain skills and to develop their career (Clary and Snyder 1999; Jacobson, Carlton, and Monroe 2012), whereas older volunteers are more likely to hold Values motivations such as wanting to share their skills and pass their knowledge on to others (Unell and Castle 2012).

Rutherford et al.'s (2019) review also notes that a few studies have looked at under-represented groups and found that for these groups, Values-related motivations, such as group identity and solidarity, were more important. Chacón et al. (2017) systematically reviewed studies that had used the VFI and found that studies that had $>50 \%$ women in their sample rated Social motivations higher than studies that had $<50 \%$ women in their sample. Other demographic characteristics such as ethnicity, class, and religion are also known to affect the types of volunteering participants engaged in, but many studies do not collect demographic information from respondents (Wilson 2012).

The limited number of citizen science studies that have attempted to examine motivations of different groups of people have also focussed primarily on variation in motivations by age, finding again that younger participants are more likely to be motivated by Egoism motivations 
such as the potential to enhance their career or reputation (Alender 2016; Ng, Duncan, and Koper 2018), to learn new things (Asingizwe et al. 2020), to have fun (Brouwer and Hessels 2019), and to learn about nature (Ganzevoort et al. 2017), whereas older participants are more likely to have Values motivations such as wanting to contribute to science and to nature conservation (Ganzevoort et al. 2017). A small number of studies have looked at other characteristics and have found that education level (Brouwer and Hessels 2019) and gender have some influence on motivations for participation (Jones et al. 2018), whereas others have not found any association between demographic characteristics and motivations (Richter et al. 2018).

\section{STUDY OF THE MOTIVATIONS OF ENVIRONMENTAL CITIZEN SCIENTISTS IN GREAT BRITAIN}

In the second part of this paper, we describe a study of the motivations of 613 environmental citizen scientists in Great Britain. Instead of looking at individual projects, as most previous studies have done (exceptions are Ganzevoort et al. 2017 and McAteer et al. 2021), we conducted a largescale survey across the field, to derive some generalisable statements about the wide range of motivations that were identified in the literature review. We then used cluster analysis to identify types of participants (i.e., groups of people who hold similar sets of motivations). Clustering target audiences according to their motivations, known as market segmentation, is commonly used in the commercial sector to tailor messages to different audiences, but it is not yet widely used in the nonprofit sector (Randle and Dolnicar 2009). Preliminary research, however, suggests that clustering of volunteers into groups can be used to promote tailored approaches to recruitment and retention (Stukas, Snyder, and Clary 2008; Lockstone-Binney et al. 2015), but to our knowledge this has not been done within citizen science. We then looked for differences in the demographic characteristics of people belonging to these different groups, exploring gender, age, ethnicity, work status, and socioeconomic group. These characteristics are known to affect participation, and so our results could be used as a tool to target recruitment to underrepresented groups. Our findings are likely to be applicable to other Western countries that show similar demographic patterns in citizen science participation.

\section{METHODS \\ NATIONAL SURVEY}

We used the market research company TNS UK Ltd (www.tnsglobal.com/united-kingdom) to run a survey of environmental citizen scientists in Great Britain. Our questions were asked as part of a weekly face-to-face survey TNS UK Ltd conducts with a large stratified sample of households in the UK (termed their Omnibus survey). Anyone can pay to have questions included. We chose this approach because it gave us access to a large number of interviewees representative of the demographics of the population of Great Britain as a whole (Table 1). This was important for our initial aim of understanding who is and who is not participating in citizen science (described in Pateman et al. 2021), and it also allowed us to explore motivations across environmental citizen science participants in Great Britain and how these vary between demographic groups. This method also allowed us to access people that targeted surveys of known citizen scientists can struggle to reach, such as those who no longer participate or those for whom project leaders do not hold contact details. Conducting the survey through a third party also helped to avoid problems of social desirability bias, where participants are inclined to provide answers they think the interviewer wants to hear (Nederhof 1985).

To identify households to survey, each week TNS selects 285 sampling areas stratified across the 12 regions of the UK by socioeconomic status and across rural/urban gradients. Within each of these areas, between 13 and 19 interviews are conducted. Recruitment is done in person by TNS's interviewers, with targets for gender and working status. Interviews are conducted between $2 \mathrm{pm}$ and $8 \mathrm{pm}$ to include people not at home during the working day (see Supplemental File 1: Survey Methodology for full details of household selection). When interviewers visit households, they explain what TNS Global is, what the interview is about, and why the household has been approached to participate. Interviews are conducted with people aged 16 and over, and interviewees are not offered incentives to participate. If they agree to take part, the interview is conducted immediately with the aid of Computer Assisted Personal Interviewing, which involves the interviewer using an electronic device to enter answers to questions. Our questions were asked in two consecutive surveys in May 2015.

TNS UK abides by the Market Research Society Code of Conduct (MRS Evidence Matters 2019), which regulates, in compliance with Data Protection and Human Rights legislation, market research activity in the UK. See Supplemental File 1: Survey Methodology for details of TNS UK's quality assurance and ethics protocols.

\section{SURVEY QUESTIONS}

For our study, survey respondents were asked, "Have you ever taken part in any type of project that involved collecting any environmental scientific information or 


\begin{tabular}{|c|c|c|c|c|}
\hline VARIABLE & GROUP & $\begin{array}{l}\text { ESTIMATED \% GB } 16+ \\
\text { POPULATION }\end{array}$ & $\begin{array}{l}\% \text { (NUMBER) IN } \\
\text { SAMPLE }\end{array}$ & $\begin{array}{l}\% \text { (NUMBER) WHO PARTICIPATED } \\
\text { IN CITIZEN SCIENCE }\end{array}$ \\
\hline Total & & & 8,220 & $7.5(613)$ \\
\hline \multirow[t]{2}{*}{ Gender } & Male & 48.5 & $47.8(3,931)$ & $8.2(323)$ \\
\hline & Female & 51.5 & $52.2(4,289)$ & $6.8(290)$ \\
\hline \multirow[t]{6}{*}{ Age } & $16-24$ & 14.4 & $15.1(1,238)$ & $7.1(88)$ \\
\hline & $25-34$ & 16.1 & $17.5(1,438)$ & $4.0(58)$ \\
\hline & $35-44$ & 17.6 & $14.6(1,199)$ & $9.1(109)$ \\
\hline & $45-54$ & 17.5 & $14.8(1,215)$ & $8.2(100)$ \\
\hline & $55-64$ & 11.9 & $12.5(1,024)$ & $9.2(94)$ \\
\hline & $65+$ & 22.4 & $25.6(2,106)$ & $7.8(164)$ \\
\hline \multirow[t]{2}{*}{ Ethnicity } & White ethnic groups & 85.6 & $85.6(7,057)$ & $8.0(565)$ \\
\hline & Minority ethnic groups & 14.4 & $13.7(1,133)$ & $4.0(45)$ \\
\hline \multirow[t]{5}{*}{ Work status } & Full-time employed & 51.2 & $32.2(2,650)$ & $8.1(214)$ \\
\hline & Part-time employed & & $14.3(1,172)$ & $7.9(92)$ \\
\hline & Unemployed & 48.8 & $17.3(1,420)$ & $3.9(55)$ \\
\hline & Retired & & $28.4(2,334)$ & $7.9(184)$ \\
\hline & In education & & $7.8(644)$ & $10.6(68)$ \\
\hline \multirow[t]{4}{*}{ Social grade } & $A B$ & 22.1 & $17.4(1,429)$ & $16.5(235)$ \\
\hline & $\mathrm{C} 1$ & 33.4 & $26.4(2,166)$ & $8.8(191)$ \\
\hline & $\mathrm{C} 2$ & 20.3 & $20.8(1,708)$ & $5.3(91)$ \\
\hline & DE & 24.2 & $35.5(2,917)$ & $3.3(96)$ \\
\hline
\end{tabular}

Table 1 Demographics of the survey sample.

Notes: Group indicates groups that interviewees were placed in for each demographic Variable. Social grade is defined by the Market Research Society (MRS Evidence Matters, undated) as higher and intermediate managerial, administrative, and professional occupations (AB); supervisory, clerical, and junior managerial, administrative, professional occupations (C1); skilled manual occupations (C2); and semi-skilled, and unskilled manual occupations, unemployed, and lowest-grade occupations (DE). Estimated \% GB 16+ population is the estimated percentage of the Great Britain over-16 population we were sampling from in each group (data provided by TNS UK Ltd as part of the survey results; for employment status, data were available only for unemployed and employed). \% (number) in sample shows the percentage (and raw number) of our 8,220 interviewees in each group. Owing to the small numbers of respondents in some categories, ethnic groups were divided into the categories of white and minority ethnic. Group numbers for ethnicity do not add up to 8,220 because some interviewees did not provide this information. \% (number) who participated in citizen science shows the percentage (and raw number) of each sample group who said they had participated in citizen science.

data?" For clarification, the interviewer added, "By this we mean national projects that help scientists like the RSPB Big Garden Birdwatch, one of the OPAL Surveys on worms, climate, tree health, biodiversity, bugs or water, or a local project." The wording of this question was designed to encompass different types of projects, from local to national. (The acronyms used would have been familiar to those who had taken part in the surveys.) Those who responded Yes to this question were asked "Why did you decide to take part in this project?" They were presented with a list of motivations for participating in citizen science and were asked to select as many as applied to them. The categories used and their derivation are shown in Figure 1, and were chosen based on the prevalence of these motivations in environmental volunteering and citizen science literature at the time of the survey. We also included an Other category to allow expression of additional motivations and Don't know/Can't remember. Those who responded No or Don't know/Can't remember took no further part in our section of the survey. TNS also collects information about the demographic characteristics of respondents and other aspects of their households that they provide to question contributors. The variables used in our study are outlined in the data analysis section below. 


\section{DATA ANALYSIS}

\section{Overall motivations for participation}

First, we used our survey data to gain a broad understanding of the relative importance of different motivations for participation across the environmental citizen science sector in Great Britain. For the subset of respondents who said they had participated in citizen science, we calculated the percentage who said that they held each motivation that was presented.

\section{Clusters of motivations}

We then used cluster analysis to investigate whether certain groups of motivations tended to be held together or whether different motivations were independent of each other. We used a hierarchical cluster analysis approach, which begins with all data points (in our case, each of the survey respondents who said they had taken part in citizen science) initially constituting their own cluster. The two survey respondents most closely resembling each other in their motivations were then combined, and this process was repeated until there was one cluster containing all of the respondents. We used Ward's method (Kaufman and Rousseeuw 1990) to determine similarities between data points, which groups the two data points that result in the smallest increase in within-cluster variance. We then selected a number of clusters to represent our data; this was a semi-arbitrary decision in which we aimed to maximise the variability in participant motivations explained and minimise the number of clusters. Other hierarchical clustering methods are available (e.g., grouping clusters based on the average or centroid value in each cluster) as well as non-hierarchical methods (e.g., k-means or fuzzy clustering); however, Mangiameli et al. (1996) applied multiple clustering methods to the same datasets, and concluded that Ward's method resulted in the largest number of observations being assigned to their correct cluster, including when the data contained outliers and large disparities in cluster density. Cluster analysis was carried out in R, using packages cluster (Maechler et al. 2013) and dendextend (Galili 2015).

\section{Variation in motivations between demographic groups}

We examined the demographics of respondents belonging to each of the clusters identified in our hierarchical cluster analysis to assess whether people with particular demographic characteristics tend to hold certain clusters of motivations for participating in citizen science. We calculated the percentage of people belonging to each cluster in different groups of the demographic characteristics age, gender, ethnicity, social grade, and work status. These variables were selected because of their effect on participation in citizen science (NASEM 2018) and in volunteering more generally (Wilson 2000). Categories of demographic variables shown in Table 1 represent the format in which we received data from TNS UK Ltd, with the exception of ethnicity. For this category, respondents could initially select from 16 groups, but because of the small numbers of participants in citizen science for some ethnic groups (14 groups had fewer than 10 respondents), we combined respondents into two groups-those identifying as being from white ethnic groups and those identifying as being from minority ethnic groups. Further details of the original ethnic groups and our groupings of these are in Supplemental File 2: Ethnicity Data.

In addition, chi-squared tests were used to determine whether people belonging to different demographic groups were more likely to hold certain motivations. One test was carried out for each unique demographic variable and motivation combination (e.g., age and wanting to help wildlife) to examine whether the distribution of people holding the motivation was even between different groups of the variable. Where test results were significant, standardised residuals were calculated, and groups for which the value was greater than two were considered to be drivers of the significant result.

\section{RESULTS}

Our survey ran for two weeks, and 8,220 people were surveyed. Table 1 shows the proportion of people from different demographic groups in this sample and in Great Britain as a whole, showing that our sample reflected the demographic makeup of Great Britain well. Of these initial survey respondents, 613 individuals had participated in citizen science and were, therefore, asked about their motivations for participating. In the participant group, the proportion of people in different demographic groups was determined by both the makeup of the initial sample (i.e., representative of the wider population) and the propensity of different groups to participate in citizen science (see Pateman et al. 2021).

\section{MOTIVATIONS FOR PARTICIPATION}

The most commonly held motivations were the Values motivations of wanting to help wildlife (most common overall), wanting to contribute to science ( $2^{\text {nd }}$ most common response), and participating because it's a valuable thing to do ( $3^{\text {rd }}$ most common response) (Figure 2). Other Values motivations of wanting to share my knowledge and wanting to help a specific site were less commonly held $\left(7^{\text {th }}\right.$ and $\left.9^{\text {th }}\right)$. Of the Egoism motivations we included, participating to learn something new was the most commonly held 


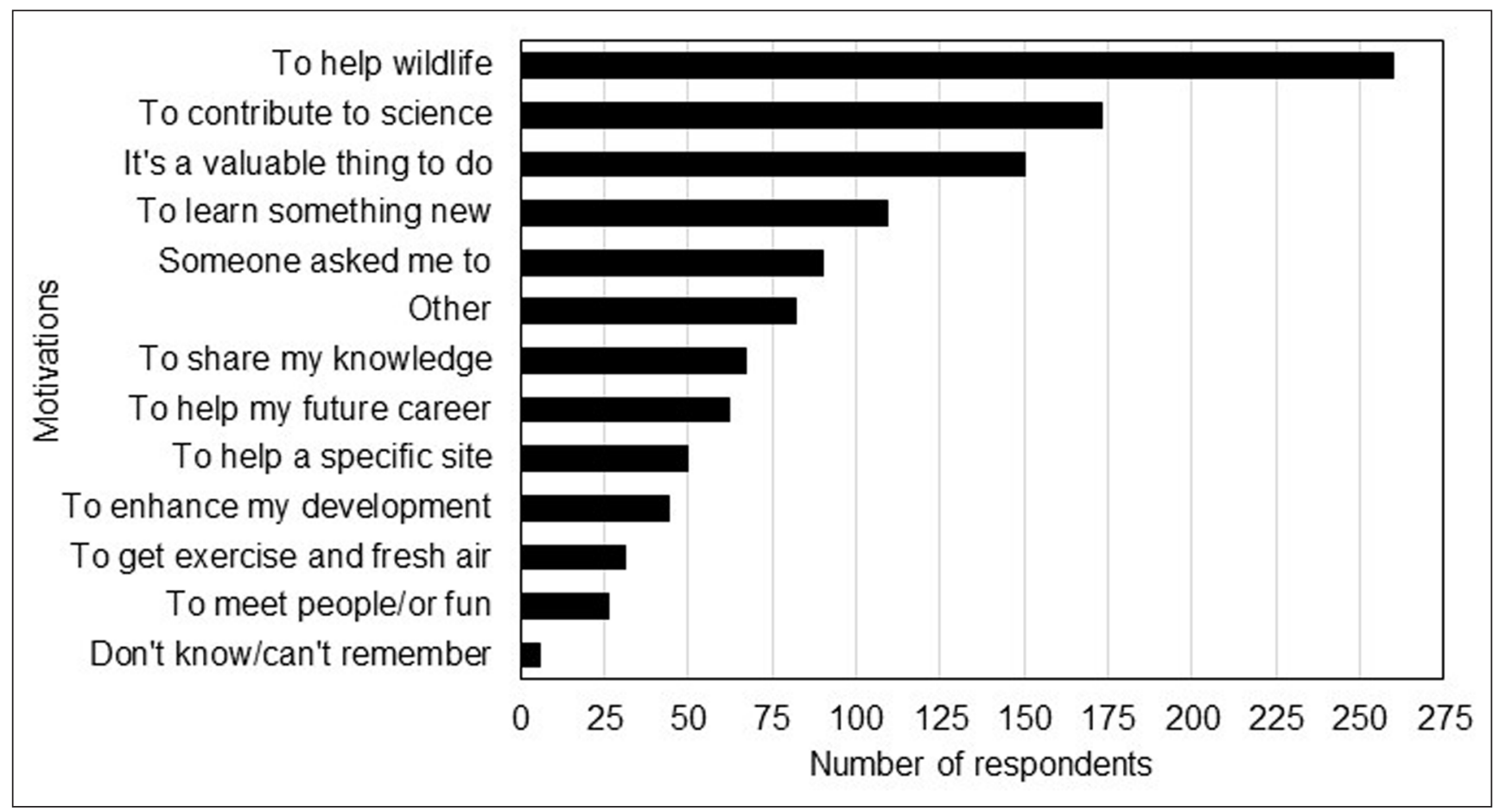

Figure 2 Number of the 613 interviewees who had participated in citizen science who said they held the motivations presented in our list.

$\left(4^{\text {th }}\right)$, followed by wanting to help my future career $\left(8^{\text {th }}\right)$, to enhance my development (10 $\left.10^{\text {th }}\right)$, and finally, to exercise and get fresh air $\left(11^{\text {th }}\right)$. The least commonly held motivation was to meet people and/or have fun (12 $\left.12^{\text {th }}\right)$. Participating because someone asked me to, and Other motivations were also common responses.

Cluster analysis of motivations revealed five groups of respondents, which explained $40 \%$ of the variation in the data. Clusters $1(n=144)$ and $5(n=111)$ were dominated by people holding Values motivations (Figure 3); cluster 1 was dominated by people who wanted to help wildlife (this motivation was held by $98 \%$ of respondents in the cluster), some of whom (22\%) also participated because it is a valuable thing to do; whereas in cluster 5, people held a broader range of Values motivations, primarily wanting to help wildlife (78\%), wanting to contribute to science (75\%), participating because it's a valuable thing to do (54\%) and to share knowledge (41\%). Cluster 3 represented the largest number of respondents (n = 228); they also held Values motivations, including wanting to help science (36\%) and participating because it is a valuable thing to do (25\%), but in addition, they commonly held Egoism motivations relating to personal development, including wanting to help one's career (23\%), wanting to learn something new (29\%), and wanting to enhance one's own development (13\%). Clusters $2(n=70)$ and $4(n=57)$ were distinct groups consisting of people who were motivated because someone else asked them to (cluster 4) or because they held other motivations not in our list (cluster 2). These respondents tended not to hold additional motivations.

\section{VARIATION IN MOTIVATIONS BY DEMOGRAPHICS}

Middle-aged and older people, women, and those identifying as being from white ethnic groups made up a greater proportion of people in clusters 1 and 5 (those dominated by people holding Values motivations) than they did in the overall sample, suggesting people from these groups are more likely to hold these types of motivations (Figure 4). Chi-squared tests support this (Table 2), showing that people identifying as from white ethnic groups were significantly more likely than people identifying as from minority ethnic groups to be motivated to help wildlife, to contribute to science, and to participate because they see it as a valuable thing to do. Chi-squared tests also showed younger people and people in education were significantly less likely to participate to help wildlife or because it is a valuable thing to do, and retired people were significantly more likely to participate because it is a valuable thing to do. We also found that women were more likely than men to participate to help wildlife.

In cluster 3, which included Egoism as well as Values motivations, we found greater proportions of younger people, people identifying as from minority ethnic groups, people in education, men, and people in lower social grades than in the overall sample, suggesting people from these groups were more likely to hold this range of motivations. Again, this was supported by results of the chi-squared tests (Table 2), which showed people identifying as from minority ethnic groups were significantly more likely to hold 


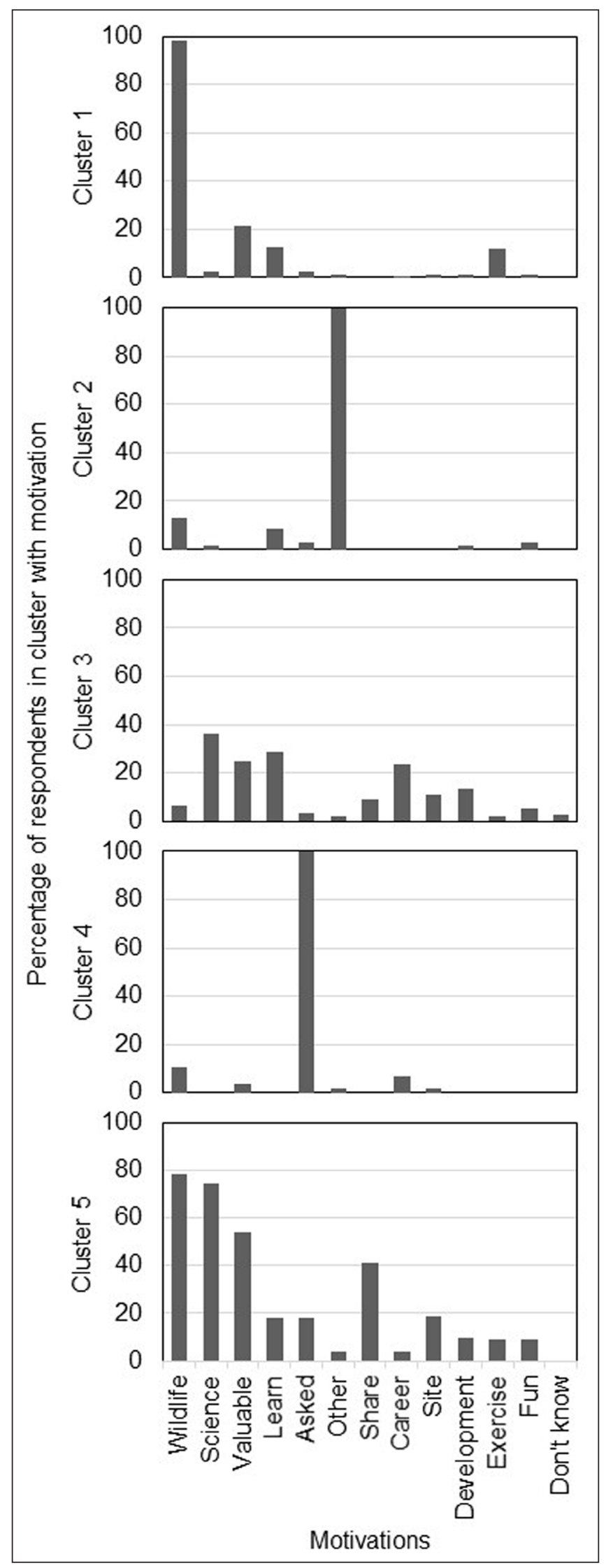

Figure 3 Percentage of people in clusters 1-5 who held each of the motivations for participating in citizen science (e.g., $98 \%$ of people in cluster 1 said that they participated to help wildlife). Because people could select multiple motivations, the total percentages for each cluster add up to more than 100. 


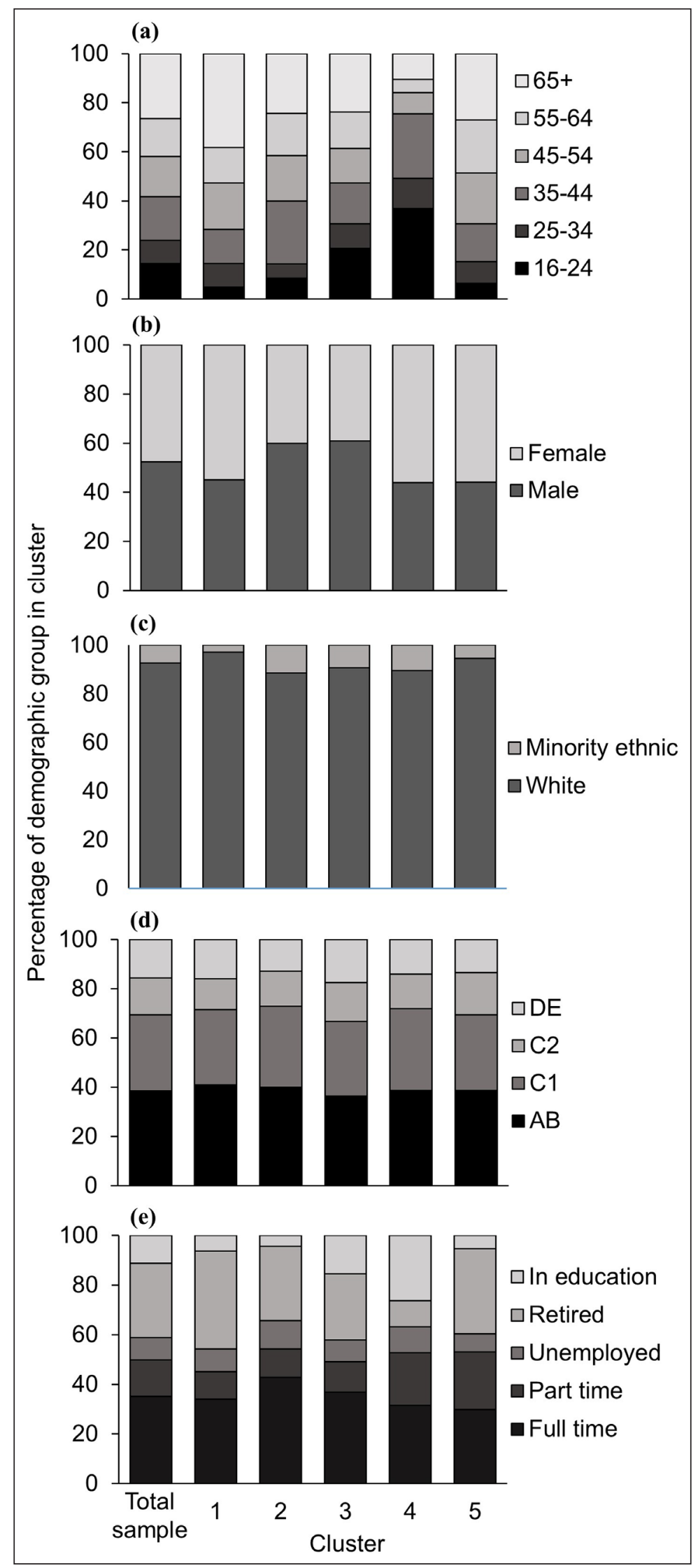

Figure 4 Proportion of people in each cluster (1-5) belonging to different groups of the variables (a) age; (b) gender; (c) ethnicity; (d) socio-economic status; and (e) employment status. Total sample shows the percentage of each demographic group in the sample of respondents who had participated in citizen science. 


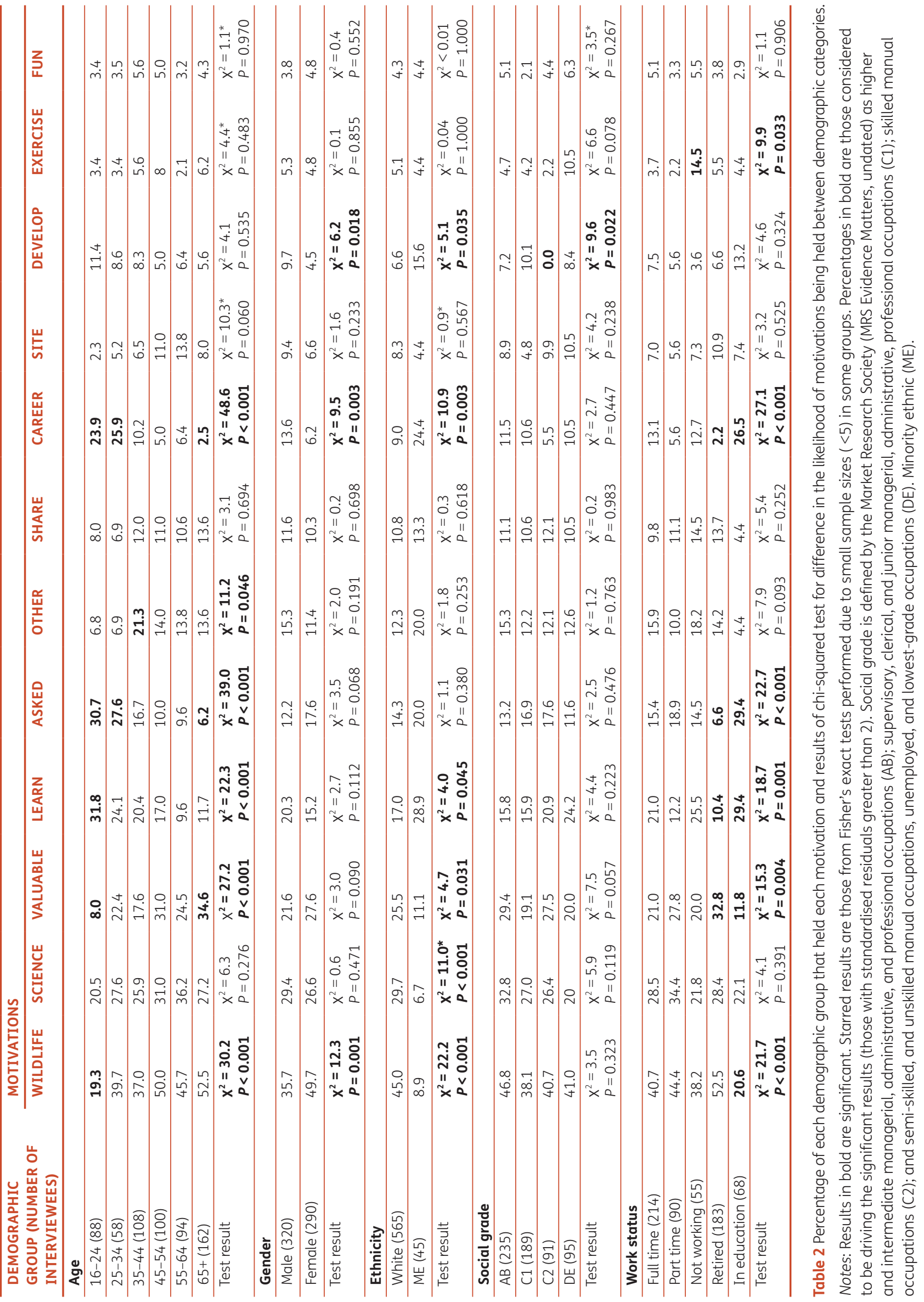


the personal development motivations of wanting to learn something, wanting to enhance their own development, and wanting to help their career than people identifying as from white ethnic groups. Men and people in social grade C2 (see Table 1 for description) were also significantly more likely to participate to enhance their own development and to help their career than women and those in other social grades. Younger people and people in education were significantly more likely to participate to learn something new and to help their career.

Clusters 2 (people with Other motivations) and 4 (people participating because someone asked them to) both had greater proportions of people identifying as from minority ethnic groups than the overall sample. Cluster 4 also had a higher proportion of people in education compared with the overall population, and chi-squared tests showed that people in the 16-24 and 25-35 age groups and those in education were significantly more likely to have participated because they were asked to, whilst retired people were significantly less likely to have participated for this reason. Cluster 2 had a higher proportion of men than in the overall sample, and cluster 4 had a higher proportion of women.

\section{DISCUSSION}

Our research has shown for the first time, through the use of cluster analysis, that different groups of environmental citizen science participants can be identified based on their motivations, and that these groups have different demographic characteristics. Values motivations were the most commonly held across our survey respondents, and have shown to be important for citizen scientists in other studies (e.g., Koss et al. 2009; Alender 2016; Pages et al. 2019). Two of our clusters were dominated by Values motivations, and these clusters had higher proportions of people from demographic groups typically overrepresented in citizen science (middle-aged and older people, those identifying as belonging to white ethnic groups, and those in higher socioeconomic groups) than the overall sample of survey respondents. A third group held Egosim motivations, such as wanting to learn something new and wanting to help one's future career, in addition to Values motivations. We found a higher proportion of people from younger age groups in this cluster than in the overall sample, reflecting findings from previous studies that younger people are more likely to hold personal development motivations (e.g., Alender 2016; Ganzevoort et al. 2017; Brouwer and Hessels 2019). We also found, however, that people belonging to minority ethnic groups and lower socio-economic groups were present in higher proportions in this group than in the overall sample of respondents. Thus, our results suggest that people from some groups thought to be typically underrepresented in citizen science are more likely to hold personal development motivations. For age and those in lower socio-economic groups, this may be driven by wanting to gain skills to help their careers, but further research is needed to explore why this might be the case for those from minority ethnic groups. In contrast to our results, Rutherford et al.'s (2019) volunteering review notes that for underrepresented groups, Values motivations were important. However, these related to group identity and solidarity, which were not reflected in our list. Citizen science projects focused on underrepresented groups have highlighted the importance of providing opportunities for groups to participate together to improve their local area (Purcell et al. 2012; Sorensen et al. 2019). Such categories should, therefore, be included in future studies of motivations.

We identified a further two groups, one comprising people who took part because someone asked them to and one of people who participated for reasons other than those presented in our list. People identifying as being from minority ethnic groups were overrepresented in these groups compared with the overall sample of survey respondents. This is in line with previous research, which has shown that people from minority ethnic groups are more likely to participate in citizen science when they are in education (Pateman et al. 2021) and when they are recruited via direct requests to participate or through community representatives (Sorensen et al. 2019).

\section{LIMITATIONS OF OUR SURVEY}

Aspects of the design of our study should be kept in mind when interpreting these results. Firstly, our initial screening question was "Have you ever taken part in any type of project that involved collecting any environmental scientific information or data?" and so our findings are most applicable to projects where participants are involved in environmental data collection (i.e., contributory projects [see Bonney et al. 2009]). It should also be noted that this question was phrased to ask people whether they had ever taken part in citizen science and so their current demographic conditions may not relate to the period during which they participated. Secondly, our survey design also meant that we had an uneven proportion of people from different demographic groups in our final sample of people who were asked about their motivations. Thus, for minority ethnic groups in particular, our results are based on a fairly small sample size. Although this still allowed us to detect significant differences in motivations held between those from white and minority ethnic groups using chi-squared tests, our results should be seen as preliminary and requiring further investigation. A larger sample would also 
allow exploration of differences in motivations between groups within our two broad groupings of white and minority ethnic, which we were not able to investigate.

Finally, our survey design meant that, for ease of completion, we gave people a list of motivations to select from based on those identified in the literature. Whilst respondents also had the option to provide a text response if they said they held Other motivations, very few respondents used this, so we were unable to gain insight into what these were. Research subsequent to our survey has also identified further motivation categories we did not include, for example, wanting to help a specific species group and helping a specific organisation (Geoghegan et al. 2016).

\section{RECOMMENDATIONS}

Participant motivations must be appealed to in order for people to want to take part in projects (Clary et al. 1994; Stukas, Snyder, and Clary 2008), and they must be fulfilled for people to continue participating. In Table 3, we have generated a list of recommendations for citizen science practitioners based on the knowledge of participant motivations we have generated in our study and from the wider literature.

\section{INSIGHT FROM THE LITERATURE OR THE STUDY RECOMMENDATION}

\section{Recruiting participants}

Clusters of motivations can be identified (this study), and can be used

Tailor recruitment materials and methods to these clusters.

to simplify the wide range of motivations that exist (see literature review) into broad groups that can be appealed to.

People from different demographic groups have different motivations, with the broad category of Values motivations being most dominant.

Egoism motivations are often important, particularly for people who are younger (this study and see literature review) and perhaps also for people from lower socio-economic groups and/or from minority ethnic groups (this study).
People in some underrepresented groups are more likely to participate because someone asked them to (this study and Brouwer and Hessels 2019).

The VFI is not exhaustive of all possible motivations (Clary and Snyder 1999, Shye 2010), with Other motivations being important for some volunteers (this study).

Cultural differences may influence motivations for participating (Bowser et al. 2014).
Design and distribute recruitment materials to appeal to a range of motivations.

Appeal to Egoism (personal benefits) motivations as well as Values (helping) motivations in recruitment materials.
Use educators and/or community leaders to promote project opportunities to under-represented groups (Pandya 2012).
Ask current and potential volunteers what motivates them, and use this to guide recruitment materials.
Conduct scoping work to understand motivations of potential participants to ensure motivations and priorities will be met (Pandya 2012; Sorensen et al 2019). Our categories in Figure 1 could be a starting point.

\begin{tabular}{ll}
\hline Retaining participants & \\
\hline $\begin{array}{l}\text { Matching motivations to volunteer tasks improves retention (Maki and } \\
\text { Snyder 2015). }\end{array}$ & Find out motivations of volunteers and tailor tasks accordingly. \\
\hline $\begin{array}{l}\text { Rewards for volunteering should match motives (Phillips and Phillips } \\
\text { 2010). }\end{array}$ & $\begin{array}{l}\text { Provide a range of rewards for volunteers to choose from (e.g., snacks, } \\
\text { t-shirts, attendance at conferences, thank you letters, and prizes) (see } \\
\text { Phillips and Phillips 2010). }\end{array}$ \\
\hline $\begin{array}{ll}\text { Motivations change over time as people move through projects (Koss } \\
\text { et al. 2009; Rotman et al. 2012; Geoghegan et al. 2016; Ganzevoort et } \\
\text { al. 2017; Cox et al. 2018, Asingizwe et al. 2020). }\end{array}$ & $\begin{array}{l}\text { Regularly ask volunteers about their motivations and consider shifting } \\
\text { tasks or rewards accordingly. }\end{array}$ \\
\hline $\begin{array}{l}\text { Egoism motivations include wanting to learn new skills or knowledge } \\
\text { and gain experiences. }\end{array}$ & $\begin{array}{l}\text { Create opportunities for gaining knowledge, skills and experiences } \\
\text { to help with career development (e.g., team working and project co- } \\
\text { ordination). Consider offering accreditation. }\end{array}$ \\
\hline $\begin{array}{l}\text { Those motivated by personal development motivations tend to } \\
\text { volunteer for less time than Values motivations (Cox et al 2018). }\end{array}$ & $\begin{array}{l}\text { Provide new and continued learning opportunities for volunteers to } \\
\text { appeal to these personal development motivations. }\end{array}$ \\
\hline $\begin{array}{l}\text { Feedback to volunteers about the value they bring to the organisation is } \\
\text { important for those with Values motivations (Phillips and Phillips 2010). }\end{array}$ & $\begin{array}{l}\text { Provide feedback about how the volunteer is helping the organisation, } \\
\text { particularly if they are motivated for values reasons. }\end{array}$ \\
\hline
\end{tabular}

Table 3 Key insights from the literature and from our research about participants' motivations and recommendations on how these can be addressed within projects. 


\section{FURTHER RESEARCH}

Although this study has enabled us to give an overview of the range of motivations held by environmental citizen scientists and how they differ between demographic groups, it is also important to note that different projects are likely to appeal to people with different motivations. Motivations of those involved in more co-created or collaborative citizen science projects (in which participants are involved in designing methods, analysing data, communicating findings, etc.), for example, may differ from those involved in collecting data and thus from the results we present here. The topic of projects is also likely to be important; Sandhaus, Kaufmann, and Ramirez-Andreotta (2019), for example, found personal motivations most important in their health-related project. Future work could, therefore, look across projects with different attributes in order to characterise participant motivations for different types of project. Such studies could also apply our approach of using cluster analysis to identify types of participants to whom recruitment material could be targeted. Furthermore, cultural differences also influence motivations. Bowser et al. (2014), for example, found that participants in the US and in India mainly held Egoism motivations, whereas for Costa Rican volunteers, there was more collective participation in collaborative projects, which was explained by a culture of contributing to the common good. Further research is needed into how motivations vary between different cultural contexts.

Studies are needed into the other motivations held by participants, as we were not able to capture these. Lack of understanding of these motivations could be problematic if we continue to design citizen science projects without taking such motivations into account or we exclude motivations held by underrepresented groups. Qualitative research should be conducted to explore these less commonly held motivations.

Finally, existing studies, including this one, have focussed on motivations of existing participants. There may be potential participants who would take part but who hold motivations that projects do not currently appeal to. Seeking out these potential participants (e.g., by looking to people participating in related activities, to ask what might motivate them to participate in citizen science) could help us to understand if the field is missing motivations that could widen the pool of participants.

\section{CONCLUSIONS}

Understanding what motivates people to volunteer is critical for encouraging their participation in citizen science projects. Our research has shown that participants hold diverse motivations, and that people from different demographic groups are likely to hold different clusters of motivations. An understanding of how motivations differ between groups is vital if practitioners want their projects to better reflect the societies in which they work. Once motivations of the target groups are understood, then recruitment strategies and retention methods can be tailored to these motivations. Further research is needed to better understand the diverse motivations of participants, to track how motivations change over time, and to discern how motivations differ between different types of citizen science projects. In addition, experimental work is needed to understand the efficacy of different recruitment and retention strategies for involving different sectors of society in citizen science projects.

\section{DATA ACCESSIBILITY STATEMENT}

Data will be deposited with the UK Data Service.

\section{SUPPLEMENTARY FILES}

The supplementary files for this article can be found as follows:

- Supplemental File 1. Survey Methodology. DOI: https:// doi.org/10.5334/cstp.370.s1

- Supplemental File 2. Ethnicity Data. DOI: https://doi. org/10.5334/cstp.370.s2

\section{ETHICS AND CONSENT}

This study gained approval by the University of York Department of Environment and Geography's Ethics Committee.

\section{ACKNOWLEDGEMENTS}

Thanks go to Chris Malley (Stockholm Environment Institute) for advice on hierarchical cluster analysis and to Jean McKendree for help with formatting the manuscript.

\section{FUNDING INFORMATION}

The survey was commissioned as part of work for the UK's Department for Environment, Food and Rural affairs, project number PH0475 "Data Submission in Citizen Science Projects." 


\section{COMPETING INTERESTS}

The authors have no competing interests to declare.

\section{AUTHOR CONTRIBUTIONS}

Alison Dyke and Sarah West designed the survey methodologies, drafted sections of the manuscript, and critically revised other sections; Rachel Pateman analysed the data; Sarah West and Rachel Pateman led the writing and revision of the manuscript. All authors gave final approval of the submitted version and agree to be accountable for aspects of the work they conducted.

\section{AUTHOR AFFILIATIONS}

Sarah West (D) orcid.org/0000-0002-2484-8124

Stockholm Environment Institute, Department of Environment and Geography, University of York, GB

Alison Dyke (D) orcid.org/0000-0003-2639-1620

Stockholm Environment Institute, Department of Environment and Geography, University of York, GB

Rachel Pateman (D) orcid.org/0000-0002-2260-170X Stockholm Environment Institute, Department of Environment and Geography, University of York, GB

\section{REFERENCES}

Aitamurto, T, Landemore, $\mathbf{H}$ and Galli, JS. 2017. Unmasking the crowd: participants' motivation factors, expectations, and profile in a crowdsourced law reform. Information Communication and Society, 20(8): 1239-1260. DOI: https:// doi.org/10.1080/1369118X.2016.1228993

Alender, B. 2016. Understanding volunteer motivations to participate in citizen science projects: a deeper look at water quality monitoring. Jcom-Journal of Science Communication, 15(3): A04. DOI: https://doi.org/10.22323/2.15030204

Asingizwe, D, Poortvliet, PM, Koenraadt, CJM, van Vliet, AJH, Ingabire, $\mathbf{C M}$, et al. 2020. Why (not) participate in citizen science? Motivational factors and barriers to participate in a citizen science program for malaria control in Rwanda. PLOS ONE, 15(8): e0237396. DOI: https://doi.org/10.1371/journal. pone.0237396

Batson, CD, Ahmad, $\mathbf{N}$ and Tsang, JA. 2002. Four motives for community involvement. Journal of Social Issues, 58(3): 429445. DOI: https://doi.org/10.1111/1540-4560.00269

Bell, S, Marzano, M, Cent, J, Kobierska, H, Podjed, D, Vandzinskaite, D, Reinert, H, Armaitiene, A, GrodzinskaJurczak, M and Mursic, R. 2008. What counts? Volunteers and their organisations in the recording and monitoring of biodiversity. Biodiversity and Conservation, 17(14): 3443-3454. DOI: https://doi.org/10.1007/s10531-008-9357-9
Bonney, R, Ballard, H, Jordan, R, McCallie, E, Phillips, T, Shirk, J and Wilderman, CC. 2009. Public participation in scientific research: Defining the field and assessing Its potential for informal science education. Washington, DC: Center for Advancement of Informal Science Education (CAISE). A CAISE Inquiry Group Report.

Bowser, A, Yurong, H, Rotman, D, Preece, J, Hansen, D, Boston, C and Hammock, J. 2014. Motivating participation in citizen science, European Conference on Social Media. University of Brighton, 10-11 July 2014. Reading: Academic Conferences and Publishing International Limited.

Brouwer, S and Hessels, LK. 2019. Increasing research impact with citizen science: The influence of recruitment strategies on sample diversity. Public Understanding of Science, 28(5): 606-621. DOI: https://doi.org/10.1177/0963662519840934

Bruyere, B and Rappe, S. 2007. Identifying the motivations of environmental volunteers. Journal of Environmental Planning and Management, 50(4): 503-516. DOI: https://doi. org/10.1080/09640560701402034

Carballo-Cárdenas, EC and Tobi, H. 2016. Citizen science regarding invasive lionfish in Dutch Caribbean MPAs: Drivers and barriers to participation. Ocean \& Coastal Management, 113: 114-127 . DOI: https://doi.org/10.1016/j. ocecoaman.2016.09.014

Chacón, F, Gutiérrez, G, Sauto, V, Vecina, ML and Pérez, A. 2017. Volunteer Functions Inventory: A systematic review. Psicothema, 29(3): 306-316. DOI: https://doi.org/10.7334/ psicothema2016.371

Clary, EG and Snyder, M. 1999. The motivations to volunteer: Theoretical and practical considerations. Current Directions in Psychological Science, 8(5): 156-159. DOI: https://doi. org/10.1111/1467-8721.00037

Clary, EG, Snyder, M, Ridge, RD, Miene, PK and Haugen, JA. 1994. Matching Messages to Motives in Persuasion: A Functional Approach to Promoting Volunteerism. Journal of Applied Social Psychology, 24(13): 1129-1146. DOI: https:// doi.org/10.1111/j.1559-1816.1994.tb01548.x

Cox, J, Oh, EY, Simmons, B, Graham, G, Greenhill, A, Lintott, C, Masters, K and Woodcock, J. 2018. Doing good online: The changing relationships between motivations, activity, and retention among online volunteers. Nonprofit and Voluntary Sector Quarterly, 47(5): 1031-1056. DOI: https://doi. org/10.1177/0899764018783066

Domroese, MC and Johnson, EA. 2017. Why watch bees? Motivations of citizen science volunteers in the Great Pollinator Project. Biological Conservation, 208: 40-47. DOI: https://doi.org/10.1016/j.biocon.2016.08.020

Finkelstien, MA. 2009. Intrinsic vs. extrinsic motivational orientations and the volunteer process. Personality and Individual Differences, 46(5-6): 653-658. DOI: https://doi. org/10.1016/j.paid.2009.01.010

Follett, R and Strezov, V. 2015. An analysis of citizen science based research: usage and publication patterns. Goffredo S, 
ed. PLOS ONE, 10(11): e0143687. DOI: https://doi.org/10.1371/ journal.pone.0143687

Galili, T. 2015. dendextend: an R package for visualizing, adjusting, and comparing trees of hierarchical clustering. Bioinformatics, 31(22): 3718-3720. DOI: https://doi. org/10.1093/bioinformatics/btv428.

Ganzevoort, W, van den Born, RJG, Halffman, W and Turnhout, S. 2017. Sharing biodiversity data: citizen scientists' concerns and motivations. Biodiversity and Conservation, 26(12): 28212837. DOI: https://doi.org/10.1007/s10531-017-1391-z

Geoghegan, H, Dyke, A, Pateman, R, West, S and Everett, G. 2016. Understanding motivations for citizen science. Final report on behalf of UKEOF, University of Reading, Stockholm Environment Institute (University of York) and University of the West of England.

Hobbs, SJ and White, PCL. 2012. Motivations and barriers in relation to community participation in biodiversity recording. Journal for Nature Conservation, 20(6): 364-373. DOI: https:// doi.org/10.1016/j.jnc.2012.08.002

Jacobson, SK, Carlton, SJ and Monroe, MC. 2012. Motivation and satisfaction of volunteers at a Florida Natural Resource Agency. Journal of Park and Recreation Administration, 30(1): 51-67. Available at https://js.sagamorepub.com/jpra/article/ view/2542 [Last accessed 31 March 2021].

Jones, MG, Childers, G, Andre, T, Corin, EN and Hite, R. 2018. Citizen scientists and non-citizen scientist hobbyists: motivation, benefits, and influences. International Journal of Science Education Part B-Communication and Public Engagement, 8(4): 287-306. DOI: https://doi.org/10.1080/215 48455.2018.1475780

Kaufman, L and Rousseeuw, P. 1990. Finding Groups in Data: An Introduction to Cluster Analysis. John Wiley \& Sons. DOI: https://doi.org/10.1002/9780470316801

Koss, R, Miller, K, Wescott, G, Bellgrove, A, Boxshall, A, McBurnie, J, Bunce, A, Gilmour, P and Ierodianconou, D. 2009. An evaluation of Sea Search as a citizen science programme in Marine Protected Areas. Pacific Conservation Biology, 15: 116-127. DOI: https://doi. org/10.1071/PC090116

Lockstone-Binney L, Holmes, K, Smith, K, Baum, T and Storer C. 2015. Are all my volunteers here to help out? Clustering event volunteers by their motivations. Event Management, 19: 461-477. DOI: https://doi.org/10.3727/15259951 5X14465748512605

Maechler, M, Rousseeuw, P, Struyf, A, Hubert, M and Hornik, K. 2013. Cluster: Cluster analysis basics and extensions. $R$ package.

Maki, A and Snyder, M. 2015. Investigating similarities and differences between volunteer behaviors: development of a volunteer interest typology. Nonprofit and Voluntary Sector Quarterly, 46(1): 5-28. DOI: https://doi. org/10.1177/0899764015619703
Mangiameli, P, Chen, SK and West, D. 1996. A comparison of SOM neural network and hierarchical clustering methods. European Journal of Operational Research, 93(2): 402-417. DOI: https://doi.org/10.1016/0377-2217(96)00038-0

McAteer, B, Flannery, W and Murtagh, B. 2021. Linking the motivations and outcomes of volunteers to understand participation in marine community science. Marine Policy, 124: 104375. DOI: https://doi.org/10.1016/j.marpol.2020.104375.

Measham, T and Barnett, G. 2008. Environmental Volunteering: motivations, modes and outcomes. Australian Geographer, 39(4): 537-552. DOI: https://doi. org/10.1080/00049180802419237

Merenlender, AM, Crall, AW, Drill, S, Prysby, M and Ballard, H. 2016. Evaluating environmental education, citizen science, and stewardship through naturalist programs. Conservation Biology, 30(6): 1255-1265. DOI: https://doi.org/10.1111/cobi.12737

MRS Evidence Matters. (undated). Definitions employed in Social Grading. Available at https://www.mrs.org.uk/pdf/Definitions\%20 used\%20in\%20Social\%20Grading\%20based\%20on\%200G7. pdf [Last accessed 20th September 2020].

National Academies of Science, Engineering and Medicine. 2018. Learning Through Citizen Science: Enhancing Opportunities by Design. Washington, DC, USA: The National Academies Press.

Nederhof, AJ. 1985. Methods of coping with social desirability bias - a review. European Journal of Social Psychology, 15(3): 263-280. DOI: https://doi.org/10.1002/ejsp.2420150303

$\mathrm{Ng}, \mathrm{C}$, Duncan, J and Koper, N. 2018. Who's "hooting"? Motivations and scientific attitudes of Manitoban citizen science owl surveyors. Avian Conservation \& Ecology, 13(2): 9. DOI: https://doi.org/10.5751/ACE-01265-130209

Pages, M, Fischer, A, van der Wal, R and Lambin, X. 2019. Empowered communities or "cheap labour"? Engaging volunteers in the rationalised management of invasive alien species in Great Britain. Journal of Environmental Management, 229: 102-111. DOI: https://doi.org/10.1016/j. jenvman.2018.06.053

Pandya, RE. 2012. A framework for engaging diverse communities in citizen science in the US. Frontiers in Ecology and the Environment, 10(6): 314-317. DOI: https://doi. org/10.1890/120007

Pateman, RM, Dyke, A, West, SE. 2021 The diversity of participants in citizen science. Citizen Science: Theory and Practice, 6(1): 9. DOI: https://doi.org/10.5334/cstp.369

Penner, LA. 2002. Dispositional and organizational influences on sustained volunteerism: An interactionist perspective. Journal of Social Issues, 58(3): 447-67. DOI: https://doi. org/10.1111/1540-4560.00270

Phillips, LC and Phillips, MH. 2010. Volunteer motivation and reward preference: An empirical study of volunteerism in a large, not for profit organisation. SAM Advanced Management Journal, Autumn 2010: 12-22. 
Raddick, M, Bracey, G, Gay, P, Lintott, C, Murray, P, Schawinski, K, Szalay, A and Vandenberg, J. 2013. Galaxy Zoo: Motivations of citizen scientists. Astronomy Education Review, 12(1): 010106. DOI: https://doi.org/10.3847/AER2011021

Richter, A, Hauck, J, Feldmann, R, Kuhn, E, Harpke, A, Hirneisen, N, Mahla, A, Settele, J and Bonn, A. 2018. The social fabric of citizen science drivers for long-term engagement in the German butterfly monitoring scheme. Journal of Insect Conservation, 22(5-6): 731-743. DOI: https://doi.org/10.1007/ s10841-018-0097-1

Rotman, D, Preece, J, Hammock, J, Procita, K, Hansen, D, Parr, C, Lewis, D and Jacobs, D. 2012. Dynamic changes in motivation in collaborative citizen-science projects. Proceedings of the ACM 2012 Conference on Computer Supported Cooperative Work. Seattle, Washington, USA. DOI: https://doi.org/10.1145/2145204.2145238

Rutherford, AC, Bu, F, Dawson, A and McCall, V. 2019. Literature review to inform the development of Scotland's Volunteering Outcomes Framework. University of Stirling report for the Scottish Government, April 2019. Available at https://www.gov. scot/publications/literature-review-scotlands-volunteeringoutcomes-framework/ [Last accessed 12 February 2021].

Sandhaus, S, Kaufmann, D and Ramirez-Andreotta, M. 2019. Public participation, trust and data sharing: gardens as hubs for citizen science and environmental health literacy efforts. International Journal of Science Education Part B-Communication and Public Engagement, 9(1): 54-71. DOI: https://doi.org/10.1080/21548455.2018.1542752

Schuttler, SG, Sorensen, AE, Jordan, RC, Cooper, C and Shwartz, A. 2018. Bridging the nature gap: can citizen science reverse the extinction of experience? Frontiers in Ecology and the Environment, 16(7): 405-411. DOI: https://doi.org/10.1002/ fee.1826

Shirk, JL, Ballard, HL, Wilderman, CC, Phillips, T, Wiggins, A, Jordan, R, McCallie, E, Minarchek, M, Lewenstein, BV, Krasny, ME and Bonney, R. 2012. Public Participation in Scientific Research: a framework for deliberate design. Ecology and Society, 17(2): 29. DOI: https://doi.org/10.5751/ES-04705170229

Shye, S. 2010. The motivation to volunteer, a systemic quality of life theory. Social Indicators Research, 98: 183-200. DOI: https://doi.org/10.1007/s11205-009-9545-3

Sorensen, AE, Jordan, RC, LaDeau, SL, Biehler, D, Wilson, S, Pitas, J-H and Leisnham, PT. 2019. Reflecting on efforts to design an inclusive citizen science project in West Baltimore. Citizen Science: Theory and Practice, 4(1): 13. DOI: https://doi. org/10.5334/cstp.170

Snyder, M and Omoto, AM. 2008. Volunteerism: social issues perspectives and social policy implications. Social Issues and Policy Review, 2(1): 1-36 DOI: https://doi.org/10.1111/j.17512409.2008.00009.x

Stukas, AA, Snyder, M and Clary, EG. 2008. The social marketing of volunteerism: A functional approach. In Haugtvedt, CP, Herr, PM, and Kardes, FR. (eds.) Handbook of consumer psychology, 1st edition. New York: Routledge, 959-979.

Toms, MP and Newson, SE. 2006. Volunteer surveys as a means of inferring trends in garden mammal populations. Mammal Review, 36(4): 309-317. DOI: https://doi.org/10.1111/j.13652907.2006.00094.x

Unell, J and Castle, R. 2012. Developing sustainable volunteering within the Natural Connections Demonstration Project: A review of evidence. Natural England Commissioned Reports, Number 096.

Van den Berg, HA, Dann, SL and Dirkx, JM. 2009. Motivations of adults for non-formal conservation education and volunteerism: Implications for programming. Applied Environmental Education and Communication, 8(1): 6-17. DOI: https://doi.org/10.1080/15330150902847328

Wald, DM, Longo, J and Dobell, AR. 2016. Design principles for engaging and retaining virtual citizen scientists. Conservation Biology, 30(3): 562-570. DOI: https://doi.org/10.1111/cobi.12627

Wehn, $\mathbf{U}$ and Almomani, A. 2019. Incentives and barriers for participation in community-based environmental monitoring and information systems: A critical analysis and integration of the literature. Environmental Science and Policy, 101: 341357. DOI: https://doi.org/10.1016/j.envsci.2019.09.002

West, SE and Pateman, RM. 2016. Recruiting and retaining participants in citizen science: what can be learned from the volunteering literature? Citizen Science: Theory and Practice, 1(2): 15. DOI: https://doi.org/10.5334/cstp.8

Wilson, J. 2000. Volunteering. Annual Review of Sociology, 26(1): 215-240. DOI: https://doi.org/10.1146/annurev. soc.26.1.215

Wright, DR, Underhill, LG, Keene, M and Knight, AT. 2015. Understanding the motivations and satisfactions of volunteers to improve the effectiveness of citizen science programs. Society \& Natural Resources, 28: 1013-1029. DOI: https://doi.org/10.1080/08941920.2015.1054976 
TO CITE THIS ARTICLE:

West, S, Dyke, A and Pateman, R. 2021. Variations in the Motivations of Environmental Citizen Scientists. Citizen Science: Theory and Practice, 6(1): 14, pp. 1-18. DOI: https://doi.org/10.5334/cstp.370

Submitted: 05 October 2020 Accepted: 02 March 2021 Published: 05 May 2021

COPYRIGHT:

(C) 2021 The Author(s). This is an open-access article distributed under the terms of the Creative Commons Attribution 4.0 International License (CC-BY 4.0), which permits unrestricted use, distribution, and reproduction in any medium, provided the original author and source are credited. See http://creativecommons.org/licenses/by/4.0/.

Citizen Science: Theory and Practice is a peer-reviewed open access journal published by Ubiquity Press.

\section{]u[ ə}

